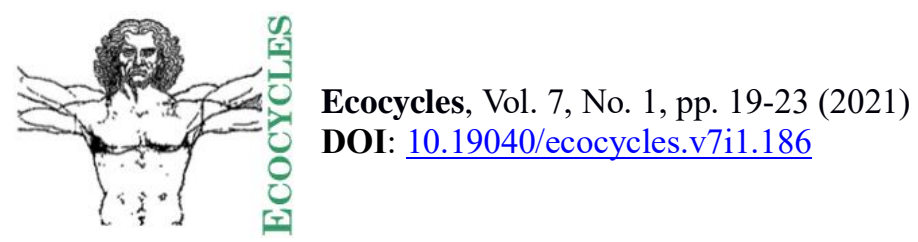

ORIGINAL ARTICLE

\title{
Drought and its impact on the bio-production of forests
}

\author{
Alice Kozumplíková, Žaneta Kalasová, Ilja Vyskot \\ Department of Environmental Studies, Mendel University in Brno, Zemědělská 1, 61300 Brno, Czech Republic \\ E-mail address: alice.kozumplikova@mendelu.cz
}

\begin{abstract}
The precipitation deficit, heat waves and subsequent drought significantly affected the forests in the Czech Republic. Primarily, forests were affected by physiological insufficiency and later by biotic and abiotic factors. On the initiative of the Ministry of the Environment of the Czech Republic, a study of the condition and damage of forest functions in the model area was formulated. The study was aimed at the model locality of the Bohemian-Moravian Highlands, especially the forest management unit of the Dačice municipality (South Bohemian Region). The study uses certified national methodologies for evaluating forest function damage (Vyskot et al. 2003; Vyskot et al. 2014). This paper specifies the state and damage of the bio-production function depending on the represented forest management groups, stand types of woody plants and age phases of stands, in terms of value (in \%) and finance in Czech koruna (CZK, the currency of the Czech Republic). In particular, spruce stands and their dominant mixtures of non-matured and fully matured trees were affected by major damage of a destructive nature. Due to the changed ecosystem conditions, a modified concept of forest management was proposed.
\end{abstract}

Keywords - forests ecosystems, functional damage, drought, forest management modification

Received: January 14, 2021

Accepted: March 8, 2021

\section{INTRODUCTION}

Large areas of the Czech Republic forests are in critical condition. Long-term natural impacts and disturbances, several-year precipitation deficit resulting in extreme drought, pandemics of insect pests, extensive damage by game and inappropriate forms of farming cause large-scale death of vegetation throughout the Czech Republic. The most affected are spruce stands, especially at lower and medium altitudes; however, the stands at the foothills are already significantly attacked. The spectrum of these disturbances also includes other types of stands (pine and deciduous trees). Unfortunately, the huge damage to forests is mostly perceived as wood losses, the impact on the so-called ecosystem functions are greatly underestimated. Forests are losing their ecological stability, resistance and resilience, water management capabilities, soil protection potential and other ecosystem and societal effects.

Not only forests in the Czech Republic suffer from the natural impacts and disturbances caused by climate change. The combination of climate change, drought periods, and expanding tree-attacking pests cause similar problems in the mountainous regions of southern Poland (Skrzecz, Perlińska, 2018). Similarly, monocultures of commercial spruce forests in Slovakia are highly damaged with the adverse effects of climate change and the prospects of such forests seem uncertain (Hlásny, Barka, Kulla, et al. 2017).
As mentioned above, the various requirements of human society attribute to forests a wide range of ecosystem as well as socio-economic functions to forests. Forests undoubtedly bring great economic and social benefits to society. In particular, the mentioned ecosystem functions, which are essential for humanity from the point of view of existence, cannot be neglected. One of the most important benefits of forest ecosystems is the ecological-stabilizing function in the landscape as well as the hydric and water management function or the ability to improve air quality (Führer 2000; Mori et al. 2016). Naturally, a forest ecosystem can create only those functions that correspond to the specific capacity of this ecosystem. Forest diversity is a key component to the creation and provision of diverse forest functions (Gamfeldt et al. 2013; Isbell et al. 2015; Morin et al. 2014).

Quantification and financial valuation of ecosystem functions and forest services is still a great challenge for society. There are many attempts to quantify the functions of natural ecosystems (Costanza et al. 1997; Daily 1997; deGroot, Wilson, Boumans 2002; Millennium Ecosystem Assessment 2005). Most of these recognized works deal with the evaluation of the complex functions of ecosystems in terms of services/benefits to society, not in terms of natural functions/effects. Nevertheless, Kline (2007) points out that the socio-economic services/benefits of the forest come from ecosystems functions/effects conditioned by natural properties and conditions of forests following the theses of 
Vyskot et al. (2003). It is the methodology "Quantification and evaluation of societal functions of forests" presents a clear procedure based on the evaluation of ecosystem functions at the level of potential abilities (real potentials) and real effects resulting from the current state of stands. The dynamics of functional effects of forest stands, its quantification and evaluation as part of the issue of ecosystem services, has already been presented by numerous studies (Vyskot, Schneider, Kozumplíková, 2016; Schneider et al. 2013; Vyskot, Kozumplíková 2018).

In response to this critical condition of forests in the Czech Republic, in 2018, the Ministry of the Environment of the Czech Republic commissioned a representative model study to assess and evaluate the condition and damage to forest functions due to changing ecosystem conditions. In cooperation with the non-profit company ENKI Třeboň and Mendel University in Brno, during the period 2018 - 2019, the study "Assessment of the state and function of forests on selected forest property in changing ecosystem conditions" was formulated, and a model part of the severely affected Bohemian-Moravian Highlands on the example of the forests in the property of the Dačice municipality was analyzed. This paper specifies the losses on the bio-production function of forests as key indicators of the ownership efficiency of the forest property management of the Dačice municipality.

\section{MATERIAL AND METHODS}

The basic characteristics and conditions of the Dačice forests (with the vegetation area of $362 \mathrm{ha}$ ) are excerpted from the Forest Management Plan (2015-2024) in force. The forest area belongs to a moderately warm and warm climatic region with an average site temperature of $6-7{ }^{\circ} \mathrm{C}$ and average precipitation of $598-750 \mathrm{~mm}$. The area of interest is formed by hills on a slightly raised level surface, mainly on gneisses. The most abundant soil type at the locality is completely dominated by acidic cambium. In terms of forest vegetation stages, the property is located from $52 \%$ in the $4^{\text {th }}$ beech forest vegetation level and from $46 \%$ in the $5^{\text {th }}$ level with fir-beech stands. The most represented target functional management groups are MG 45 (nutrient habitats of middle positions; $142.71 \mathrm{ha}$ ) and MG 55 (nutrient habitats of higher positions; $76.75 \mathrm{ha})$.

Changes in the climatic conditions of the Dačice forests are documented by data on the course and dynamics of precipitation (Fig. 1) and by comparing the annual course of temperatures in the periods 1901-1949 and 2014-2018 (Fig. 2). Precipitation and temperature extremes of the period 2014-2018 are quite convincing especially in the, especially in the active vegetation season.

The certified methodology of the Ministry of the Environment of the Czech Republic was used to solve this study (Vyskot et al. 2003; Vyskot et al. 2014). Due to the scope of methodological procedures, only the main steps of the solution are given:
1) definition of ecosystem functional units of the forest functional management groups (FMG), functional stand types (FST), age levels (AL);

2) determination of real potentials of forest functions;

3) determination of real effects (effects) of forest functions;

4) determination of damage values to forest functions;

5) financial expression of the value of forest functions;

6) financial expression of damage to forest functions;

7) proposal of conceptual measures for the forests of the municipality of Dačice.

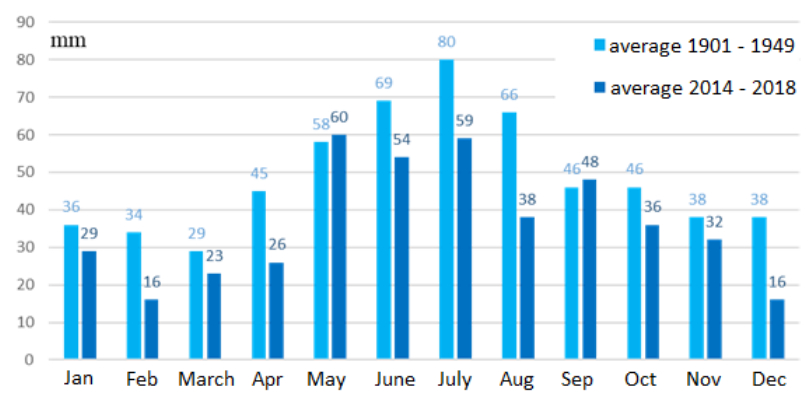

Figure 1. Comparison of average precipitation between 19011949 and 2014-2018 (Forest Management Plan, 2018)

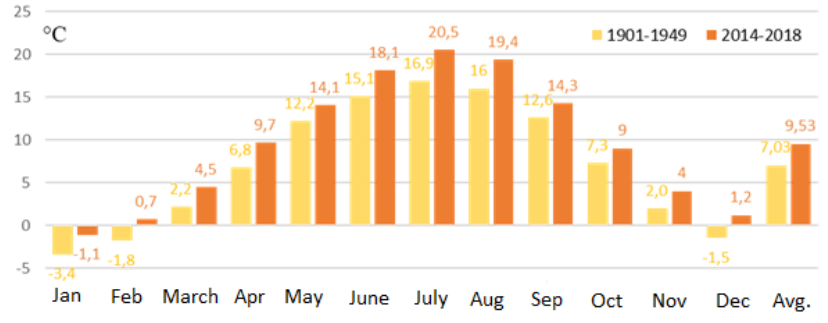

Figure 2. Comparison of the annual course of temperatures in the periods 1901-1949 and 2014-2018; (CHMI, 2018)

Due to the extraordinary number of stand groups, we specify the damage to the bio-production function quantitatively (in $\%$ ) and its financial loss (in CZK) within the so-called higher forest levels - according to represented functional management groups (FMG), functional stand types (FST), age levels (AL).

\section{RESULTS AND DISCUSSION}

The study evaluated and quantified the damage and losses in all forest functions of the Dačice municipality in the period 2015 - 2018. These are ecosystem functions of bioproduction, ecological-stabilization, hydric-water management, edaphic-soil protection. Their overview and value and financial interpretation are beyond the scope of this paper, only the above reasonably announced bio-production function is presented.

The significant losses in the bio-production of forest ecosystems have been documented, not only in wood but also in the biomass of its potential. The total financial expression of the amount of damage to the bio-production function of the forests of the Dačice municipality is 33,350 ths. of CZK. 
However, the bio-production function damage of selected forest stands is significantly differentiated. Changing ecosystem conditions are very heterogeneous, including the reactions of forest stands, woody plants and their mixtures as well.

A detailed evaluation of the potential and the current effect of the bio-production function was elaborated in detail within the study at the level of individual stand types. It was thus possible to monitor the reactions of individual tree species and tree mixtures to changes in habitat and climatic conditions as well as the condition, forms of damage and the level of destruction.

The state of bio-production damage in individual age levels of stands is strongly evident (Fig. 3).

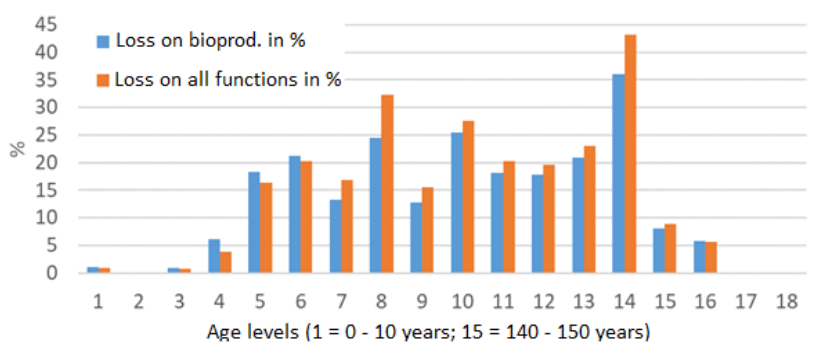

Figure 3. Damage (\%) to the bio-production function and all forest functions according to the age level of forest stands

There is an obvious increase in damage and destruction with increasing age from about 50 years to overaged trees. It is obvious that the ecological and physiological stability of forest stands from juvenile resilience to adult resistance is fundamentally declining and degrading. Analogous results can be observed in the financially expressed loss on the bioproduction function (expressed in thousands of CZK) again according to FMG (Fig. 4), FST (Fig. 5) and AL (Fig. 6).

The financially expressed bio-production loss according to the functional management groups proves that out of the total financial loss 33,350 ths. CZK, approximately CZK 25 million is concentrated in FMG 45 and 55.

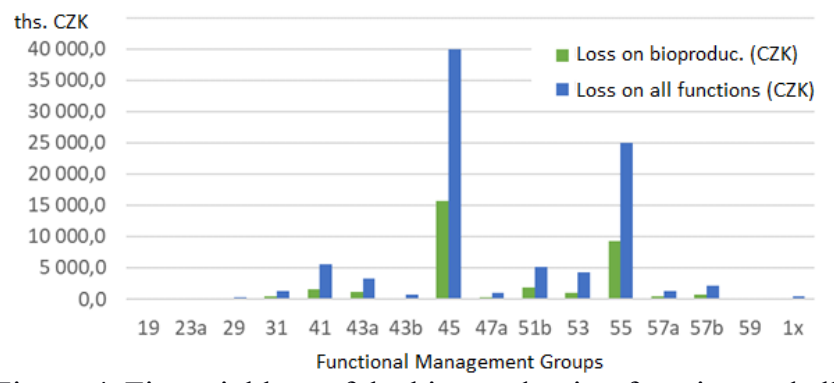

Figure 4. Financial loss of the bio-production function and all forest functions according to the FMGs

From the point of view of specific stand types (Fig. 5), it is obvious that approx. 15 million CZK of bio-production losses are in pure spruces, another 11 million CZK in dominant and majority spruce mixtures.
Financial bio-production losses by age (Fig. 6) are significant in relation to the continued existence and development of stands. The dominant losses are in the phases of already production effects of stands, with fundamental impacts on the efficiency of forest owner management, dependent on the profitability of the business.

The above overviews show that spruce stands were most affected by the change in ecosystem conditions (2015-2018). Vegetation type $\mathrm{C} 1$ is affected by more than $35 \%$ of the area with almost $60 \%$ frequency. The vegetation types of spruce with fir and pine are also strongly degraded. Oak and beech stand types do not show significant health damage. Stands' health degradation from the point of view of developmental stages of vegetation is in area and percentage low in the youngest age stages (up to 30 years of age there is no significant evidence of damage). With increasing age, the health condition deteriorates sharply. Age levels $60+$ are significantly attacked, the gradation is in the age of 80 . Overaged stands (almost 100\% of the area) are destroyed.

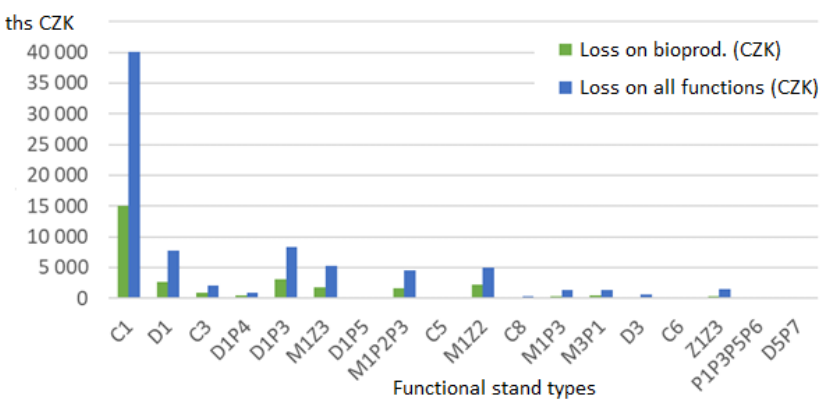

Figure 5. Financial loss of the bio-production function and all forest functions according to the FSTs (where: C - pure stands, D - with one dominant tree species, M1 - with the majority of the one tree species; 1 - spruce, 2 - fir, 3 - pine, 4 - beech, 5 - oak etc.)

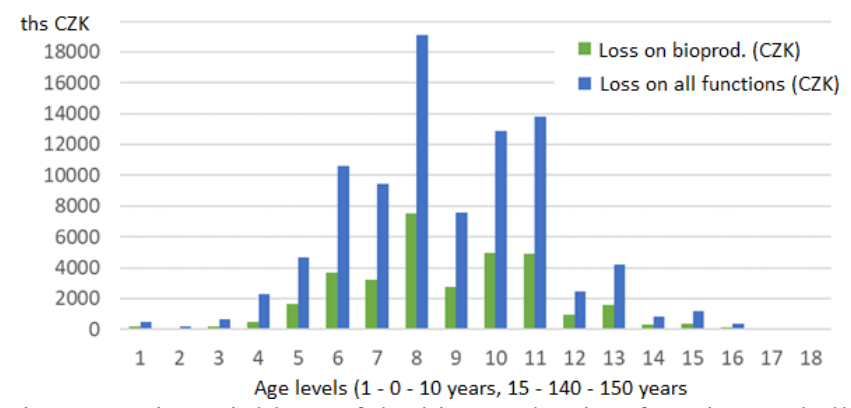

Figure 6. Financial loss of the bio-production function and all forest functions according to the ALs

\section{The basis for economic decisions by the owner}

The response of the forest owner and forest manager to the degradation and devastation of forest property by synergies of disturbances means drastic measures in the transformation of species vegetation composition, age and spatial structure of vegetation depending on changed climatic, growth and thus habitat conditions (transposition of vegetation stages, forest types, etc.). 
However, forestry management measures mean a long-term process of gradual steps and transformations with demanding transition phases. For the transition phases, it is necessary to use the existing elements and segments of as yet unaffected or little-affected habitats and vegetation types.

At the request of the forest manager, forest segments (stand types at specific habitats) were evaluated, which even in changed climatic and growth conditions are not demonstrably impacted and can currently be used as basic axes of necessary transformations and reconstructions of stands. These are stands with pine, oak, beech and their mixtures with spruce.

\section{Proposal of conceptual measures}

The proposed measures are based on the findings of the study and respect current changes in natural conditions to correct the condition of forests. The results of the survey of the condition of forests, assessment and evaluation of their value parameters of ecosystem functions and their damage are the source determinants of concept proposals and changes in management. The bio-production function is closely linked to other ecosystem functions. Therefore, forestry conceptual measures cannot be functionally differentiated but integrated.

The strategy for adapting management principles to climate and habitat change includes:

- habitat shift of vegetation stages;

- revision of typological units;

- changes in the target species composition;

- modifications to the management framework directives, in particular: reduction of washing of specific tree species; woody and spatially varied vegetation mixtures; heterogeneous group mixing $(0.20 \mathrm{ha})$; woody dominance of oak and beech.

\section{CONCLUSIONS}

The proposed management modifications fully respect changes in ecosystem conditions (climate change, vegetation conditions, water regime of vegetation and soil, biotic and abiotic harmful factors). Therefore, they cannot fully correspond to binding state and departmental directives and, on the contrary, they must respect the owner and a knowledgeable forest manager.

Forests in the Czech Republic are the country's life-giving resource. They require a new functionally integrated concept, approach and forms of management. A model analysis of the forests of the Dačice municipality could help with these solutions.

\section{OPEN ACCESS STATEMENT}

This article has been published under a Creative Commons Attribution 4.0 international license that provides immediate open access to its content on the principle that making research freely available to the public supports a greater global exchange of knowledge.

\section{ACKNOWLEDGEMENTS}

The contribution was supported by a contract research project of the Ministry of the Environment of the Czech Republic (contract registration number 180040) entitled "Assessment of the condition and function of forests on selected forest property in changing ecosystem conditions".

\section{REFERENCES}

Costanza, R., d'Arge, R., de Groot, R. et al. 1997. The value of the world's ecosystem services and natural capital. Nature 387, 253-260.

DOI: $\underline{10.1038 / 387253 \mathrm{a} 0}$

Daily G. C. (Ed.) 1997. Nature's services. Societal dependence on natural ecosystems. Island Press, Washington, DC. $392 \mathrm{p}$.

DeGroot R., Wilson M.A., Boumans R.M. 2002. A typology for the classification, description and valuation of ecosystem functions, goods and services. Ecol. Econ. 41 (3), 393-408. DOI: $\underline{10.1016 / \mathrm{S} 0921-8009(02) 00089-7}$

Führer, E. 2000. Forest functions, ecosystem stability and management. Forest Ecology and Management. 132(1), 2938.

DOI: $\underline{10.1016 / \mathrm{S} 0378-1127(00) 00377-7}$

Gamfeldt, L., Snall, T., Bagchi, R., Jonsson, M., Gustafsson, L., Kjellander, P. et al. 2013. Higher levels of multiple ecosystem services are found in forests with more tree species. Nature Communications, 4, 1340.

DOI: $\underline{10.1038 / \mathrm{ncomms} 2328}$

Hlásny, T., Barka, I., Kulla, L. et al. 2017. Sustainable forest management in a mountain region in the Central Western Carpathians, northeastern Slovakia: the role of climate change. Reg Environ Change 17, 65-77.

DOI: $\underline{10.1007 / \mathrm{s} 10113-015-0894-\mathrm{y}}$

Isbell, F., Craven, D., Connolly, J., et al. Biodiversity increases the resistance of ecosystem productivity to climate extremes. Nature. 2015, 526(7574), 574-577.

DOI: $\underline{10.1038 / \text { nature } 15374}$

Kline, J. D. 2007. Defining an economics research program to describe and evaluate ecosystem services. Gen. Tech. Rep. PNW-GTR-700. Portland, OR: U.S. Department of Agriculture, Forest Service, Pacific Northwest Research Station. $46 \mathrm{p}$.

DOI: $10.2737 / P N W-G T R-700$

Millennium Ecosystem Assessment 2005. Ecosystems and Human Well-being: Current State and Trends, Washington DC: Island Press.

Morin, X., Fahse, L., de Mazancourt, C., Scherer-Lorenzen, M. \& Bugmann, H. 2014. Temporal stability in forest 
productivity increases with tree diversity due to asynchrony in species dynamics. Ecology Letters, 17, 1526-1535.

DOI: $10.1111 /$ ele. 12357

Schneider, J., Vyskot, I., Lampartová, I., Kozumplíková, A., Lorencová, H. 2013. Practical experiences with ecosystem evaluation of forest functions in the Czech and Slovak Republics. In Grega, L., Karber, V., Konopáč, V. ICABR Abstracts. Brno: Mendelova univerzita v Brně, 2013, 489501.

https://www.researchgate.net/publication/261759385_Practi cal_experiences_with_ecosystem_evaluation_of_forest_fun ctions_in_the_Czech_and_Slovak_Republics

Skrzecz, I., Perlińska, A. 2018. Current Problems and Tasks of Forest Protection in Poland. Folia Forestalia Polonica, 60, 3, 161-172.

DOI: $10.2478 / \mathrm{ffp}-2018-0016$

Vyskot, I. et al. 2003. Quantification and evaluation of forest functions in the Czech Republic. MoE CR, Prague, 186 pp.
https://www.researchgate.net/publication/273946492_Quant ification_and_Evaluation_of_Forest_Functions_on_the_Exa mple_of_the_Czech_Republic

Vyskot, I. et al. 2014. Ecological and economic evaluation of societal functions of alternatively structural types of forests. Certified methodology, MoE CR, Prague, 78 pp. (in Czech).

Vyskot, I., Kozumplíková, A. 2018. Losses of hydric-water management and ecological-stabilization forest function: Example of "Urban forests Dačice". In Rožnovský, J., Litschmann, T. (eds): Hospodaření s vodou v krajině, Třeboň 21-22. 6. 2018. (in Czech).

http://www.cbks.cz/SbornikTrebon2019/Vyskot_Kozumplik ova_Kalasova.pdf

Vyskot, I., Schneider, J., Kozumplíková, A. 2016. Dynamics of the functional effect of forest stands within ecosystem services problematics. Reports of forestry research, 61(2), 8189 (in Czech).

http://www.vulhm.cz//sites/File/ZLV/fulltext/438.pdf.

(C) 2021 by the author(s). This article is an open-access article distributed under the terms and conditions of the Creative Commons Attribution (CC BY) license (http://creativecommons.org/licenses/by/4.0/). 